\title{
METAL STATE ALTERATION IN Fe PHTHALOCYANINE
}

\author{
A. Amulevičius, V. Remeikis, and A. Undzėnas \\ Institute of Physics, Savanoriu 231, LT-02300 Vilnius, Lithuania \\ E-mail: antanas@ar.fi.lt
}

Received 28 February 2007; revised 10 May 2007

\begin{abstract}
${ }^{57} \mathrm{Fe}$ isotope-enriched iron phthalocyanine has been synthesized and studied by the Mössbauer spectroscopy in the temperature range 100-350 K. The intermediate $\mathrm{Fe}$ oxidation states have been observed and it has been found that the rate of charge redistribution is temperature-dependent. The correlation between the temperature behaviour of the isomeric shift and quadrupole splitting has been demonstrated. The Fe oxidation states are associated with fluctuations of electron charges, electron-accepting and electron-donating properties of surrounding ligands. The energy barriers separating Fe oxidation states have been determined.
\end{abstract}

Keywords: Mössbauer spectroscopy, isomeric shift, quadrupole splitting, iron phthalocyanine, Fe oxidation states

PACS: $33.45 .+\mathrm{x}, 34.50 . \mathrm{Gb}, 32.10 . \mathrm{Fn}$

\section{Introduction}

Metal phthalocyanines are representatives of porphyrin molecules and are a family of aromatic macrocycles based on a delocalized two-dimensional $\pi$-electron system displaying a large number of unique properties. Phthalocyanines are highly stable, nontoxic materials having strong absorption in a visible spectral region, and because of quite high photoconductivity, they are promising materials to be used in optoelectronic devices [1-4]. It is known that various kinds of metals can coordinate to the centre of their large aromatic rings and markedly change the properties of the molecule. Valence electron densities in coordination compounds under the influence of external and internal factors, even at the same chemical (atomic) shortrange order, may be distributed in different ways. The electron density distribution in molecular bonds predetermines electric, magnetic, and optical properties of organic material [5-8]. Iron phthalocyanine attracted attention as a test molecule close to the iron (haem) proteins because of their structural similarity $[9,10]$. The expected iron oxidation number in such compounds is equal to 2, although the postulation of the particular value of this parameter based on an electronic structure of iron atoms is quite problematic. If there are electronaccepting ligands attached to the molecule macrocycle, $\mathrm{Fe}^{3+}$ ions along with $\mathrm{Fe}^{2+}$ ions are observed in Mössbauer spectra by their respective quadrupole doublets. Mössbauer spectroscopy easily identifies the iron oxidation number since the Mössbauer isomeric shift $(\delta)$ and quadrupole splitting $(\Delta Q)$ values for $\mathrm{Fe}^{2+}$ and $\mathrm{Fe}^{3+}$ ions differ markedly $[10,11]$. It is experimentally possible in iron phthalocyanines to study the electronic density redistribution between iron ions and surrounding nitrogen or other atoms and ligand rings. The principal aim is to establish whether there are stable ionization levels of iron ions and how their dynamic change takes place, how surrounding donor and acceptor centres affect the charge transfer in iron. This can be done using Mössbauer spectroscopy methods.

\section{Materials and methods}

The molecular structure of iron phthalocyanine is presented in Fig. 1. ${ }^{57} \mathrm{Fe}$ phthalocyanine has been synthesized by a procedure described in [12]. X-ray diffractograms showed characteristic peaks of $\beta$-form crystals. Samples were free from nanoparticles of iron or traces of other magnetic phases. Mössbauer spectra were obtained with a conventional spectrometer in transmission geometry. All isomer shifts are given with respect to that of $\alpha-\mathrm{Fe}$. Spectra of samples were recorded in a special vacuum cryostat at $100-350 \mathrm{~K}$. The typical Mössbauer spectra are presented in Fig. 2.

Applying the macroatom model $[13,14]$, we tried to evaluate the tendency of charge redistribution in the 


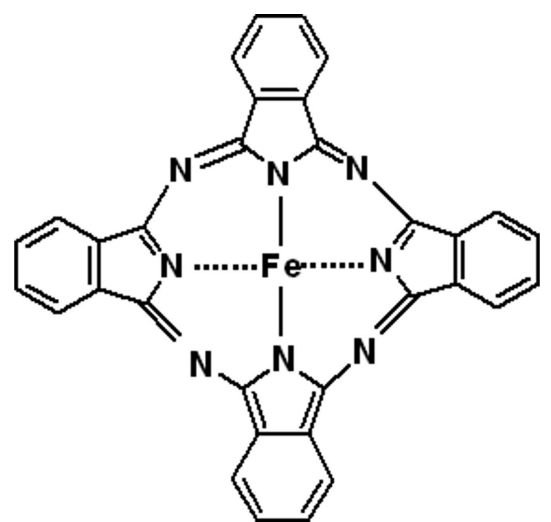

Fig. 1. Molecular structure of iron phthalocyanine.

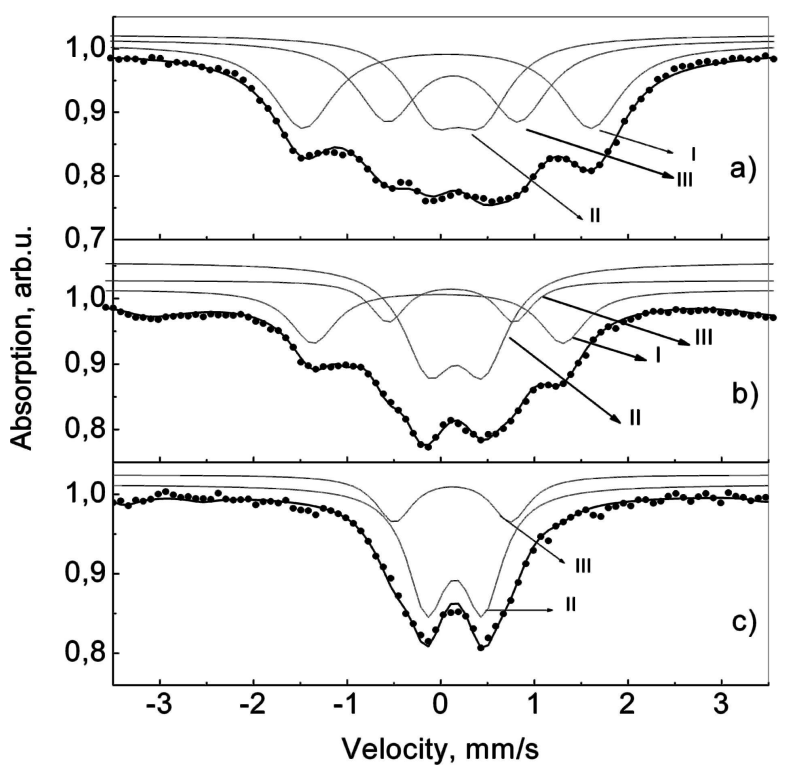

Fig. 2. Mössbauer spectra of the sample obtained at (a) $100 \mathrm{~K}$, (b) $300 \mathrm{~K}$, and (c) $340 \mathrm{~K}: I-I I I$ are subspectra for $\mathrm{Fe}$ of various oxidation numbers ( $I$ for $\mathrm{Fe}^{2+}, I I$ for $\mathrm{Fe}^{3+}, I I I$ for $\mathrm{Fe}^{2.5+}$ ). Points are experimental data.

$\mathrm{Fe}-\mathrm{N}$ system and the dependence of the arising isomeric shift on the properties of atoms:

$$
\begin{aligned}
\delta= & C_{\mathrm{N}}^{\mathrm{s}}\left\{P\left(\Phi_{\mathrm{N}}^{*}-\Phi_{\mathrm{Fe}}^{*}\right)\right. \\
& \left.+Q\left(\frac{n_{\mathrm{w}-\mathrm{z}}^{\mathrm{N}}-n_{\mathrm{w}-\mathrm{z}}^{\mathrm{Fe}}}{n_{\mathrm{w}-\mathrm{z}}^{\mathrm{Fe}}}\right)+\Delta \delta_{\mathrm{v}}\right\},
\end{aligned}
$$

where $\Phi^{*}$ is the electron work function of $\mathrm{Fe}$ and $\mathrm{N}$ atoms; $n_{\mathrm{w}-\mathrm{z}}$ is the electronic density within the limits of Wigner-Seitz cells, $P=-0.75 ; Q=1.75$ is a constant for all $\mathrm{Fe}$ alloys, and its dimension is such that $\delta$ values are reported in $\mathrm{mm} / \mathrm{s} ; C_{\mathrm{N}}^{\mathrm{s}}$ and $\left(1-C_{\mathrm{Fe}}^{\mathrm{s}}\right)$ are surface concentrations of $\mathrm{Fe}$ and $\mathrm{N}$ atoms $\left(S=V^{2 / 3}\right), V$ is the molar volume. The term $P\left(\Phi_{\mathrm{N}}^{*}-\Phi_{\mathrm{Fe}}^{*}\right)$ indicates the direction and amount of the transferred charge, the term $\left(n_{\mathrm{w}-\mathrm{z}}^{\mathrm{N}}-n_{\mathrm{w}-\mathrm{z}}^{\mathrm{Fe}}\right) / n_{\mathrm{w}-\mathrm{z}}^{\mathrm{Fe}}$ determines the $s-d$ electron hybridization (covalency) contribution to $\delta$. The ion volume mismatch correction can be expressed as follows:

$$
\begin{aligned}
\Delta \delta_{\mathrm{v}}= & C_{\mathrm{N}}^{\mathrm{s}}\left(\frac{0.615 \cdot E_{\mathrm{N}}}{0.615 \cdot E_{\mathrm{N}}+E_{\mathrm{Fe}}}\right. \\
& \left.\cdot \frac{V_{\mathrm{N}}-V_{\mathrm{Fe}}}{V_{\mathrm{Fe}}} \cdot \frac{\partial \delta}{\partial \ln V}\right),
\end{aligned}
$$

where $E$ are elastic moduli, $\partial \delta / \partial \ln V$ is a calibration constant $(1.33 \mathrm{~mm} / \mathrm{s})$.

The isomeric shift reflects the $s$ electron density changes at the Fe nucleus. The $\delta$ value tells nothing directly about a $4 s$ electron number in the atom since a portion of $4 s$ electron charge is screened by $3 d$ electrons. As direct quantum-mechanical calculations are rather complex, we will make use of the following quasiempirical expression to describe the relation between $\Delta n_{3 d}, \Delta n_{4 s}$, and $\Delta \delta$ [13]:

$$
\Delta \delta=-2.05 \Delta n_{4 s}+1.25 \Delta n_{3 d},
$$

where $\Delta \delta$ is the change in the Mössbauer isomer shift caused by changes in the number of the $4 s$ or $3 d$ electrons in the $\mathrm{Fe}$ atom. The coupling constant for isomeric shift is $-2.05 \mathrm{~mm} / \mathrm{s}$ for one $4 s$ electron and $1.25 \mathrm{~mm} / \mathrm{s}$ for one $3 d$ electron. The $\delta$ value is the smaller, the larger the $s$ electron density at the nucleus is. The energy barriers can be assessed by employing the equilibrium population expression that is used in magnetic resonance theory [15]:

$$
\frac{n_{A}-n_{B}}{n_{A}+n_{B}}=\frac{\Delta E}{2 k_{\mathrm{B}} T}
$$

where $n_{A}$ and $n_{B}$ are relative populations of oxidation states, $\Delta E$ is an energy barrier separating corresponding oxidation states, $k_{\mathrm{B}}$ is the Boltzmann constant, $T$ is temperature. We can find the lifetimes of oxidation states by employing the Bloch equation solution describing the population of oxidation states [15]:

$$
n=n_{0}\left(1-\mathrm{e}^{-t / \tau_{N}}\right),
$$

where $n$ is the relative state population, $n_{0}$ is a total number of states, $t$ is the state lifetime, $\tau_{N}$ is the lifetime of the Mössbauer excited state $\left(10^{-7} \mathrm{~s}\right)$.

\section{Results and discussion}

Vibrations of molecules and their fragments can cause electronic density perturbations in organic molecular systems. The frequency of these processes is in the 
Table 1. Iron oxidation numbers at different temperatures and changes in $4 \mathrm{~s}$ and $3 d$ electron number corresponding to experimental isomeric shift and quadrupole splitting.

\begin{tabular}{crrrrrr}
\hline & \multicolumn{2}{c}{$\mathrm{Fe}^{2+}$} & \multicolumn{2}{c}{$\mathrm{Fe}^{2.5+}$} & \multicolumn{2}{c}{$\mathrm{Fe}^{3+}$} \\
\cline { 2 - 7 } Temperature & $\Delta n_{4 s}$ & $\Delta n_{3 d}$ & $\Delta n_{4 s}$ & $\Delta n_{3 d}$ & $\Delta n_{4 s}$ & $\Delta n_{3 d}$ \\
\hline $100 \mathrm{~K}$ & 0.035 & 0.41 & -0.13 & 0.22 & -0.22 & 0.06 \\
$220 \mathrm{~K}$ & 0.039 & 0.35 & -0.12 & 0.19 & -0.16 & 0.07 \\
$300 \mathrm{~K}$ & -0.004 & -0.06 & -0.01 & -0.02 & 0.06 & -0.01 \\
\hline
\end{tabular}

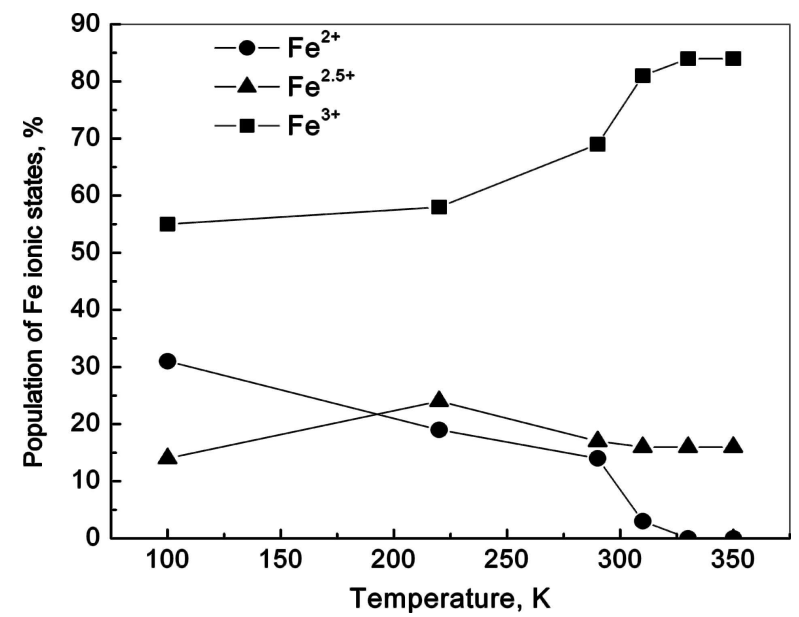

Fig. 3. The relative population of Fe ionic states at different temperatures. $\square$ mark the overall amount of $\mathrm{Fe}^{3+}$ ions, $\boldsymbol{\Delta}$ mark the population of the intermediate $\mathrm{Fe}^{2.5+}$ state, $\bullet$ mark the amount of $\mathrm{Fe}^{2+}$ ions.

range $10^{10}-10^{13} \mathrm{~s}^{-1}$ and the Mössbauer spectra provide a picture of the time-averaged charge redistribution.

At low temperatures $(T \leq 200 \mathrm{~K})$, the Mössbauer spectra (Fig. 2) can be approximated by three quadrupole doublets $(I-I I I)$. Population probabilities of ion states at various temperatures are presented in Fig. 3.

Let us assume that the chemical short-range order is the same for all iron ions and it is temperatureindependent, but the iron oxidation number may change as a result of fluctuations of valence electron charges. The charge fluctuations occur between $\mathrm{Fe}$ ions and nitrogen atoms in indole rings. The show-up of spectral lines of $\mathrm{Fe}^{3+}$ ions suggests that electron-donating and electron-accepting properties of ligands can affect the central ion oxidation number. The separating energy barrier determines the lifetime of different oxidation states and it becomes more transparent with increasing temperature. The transition from $\mathrm{Fe}^{2+}$ to $\mathrm{Fe}^{3+}$ state takes place during the phonon-assisted activation process via the nitrogen ring.

According to the macroatom model $[13,14]$, the $\delta$ value in the $\mathrm{Fe}-\mathrm{N}$ system is $0.52 \mathrm{~mm} / \mathrm{s}$ (Eqs. (1) and
(3)). This value corresponds to electron population changes in Fe ion orbitals: the charge density probability drops in the $4 s$ orbital, and that of the $3 d$ orbital increases, by 0.21 and 0.007 of the elementary charge unit, respectively. The volume correction (Eq. (2)) is about $-0.08 \mathrm{~mm} / \mathrm{s}$ and it indicates that the $\mathrm{Fe}$ atom shell is being compressed by the surrounding nitrogen atoms. At the surface area ratio of iron atoms and surrounding nitrogen atoms of about $0.2-0.3$, the $\delta$ values are $0.35-0.55 \mathrm{~mm} / \mathrm{s}$ and are close to experimental ones.

The above-said implies the charge transfer tendency in metal phthalocyanines. As can be seen in Fig. 4, $\delta$ and $\Delta Q$ for all iron ions increase with lowering temperature, though the quadrupole splitting of $\mathrm{Fe}^{3+}$ ions behaves differently than that of $\mathrm{Fe}^{2+}$ and $\mathrm{Fe}^{2.5+}$ ions. $\Delta n_{3 d}$ and $\Delta n_{4 s}$ electron number alterations corresponding to experimental values of $\Delta \delta$ at various temperatures are presented in Table 1. Calculations were carried out using Eq. (3). In an attempt to separate contributions of $\Delta n_{3 d}$ and $\Delta n_{4 s}$ electron charges to alterations of the charge distribution, let us perform an analysis of experimental values of quadrupole splitting. The $d$ electron density distribution is spherically symmetrical and creates no gradient of an electric field (EFG) as well as no quadrupole splitting in the nucleus. The main source of the EFG is uncompensated charges of $3 d$ electrons. One uncompensated $3 d$ electron charge can create the EFG of about $5 \cdot 10^{21} \mathrm{~V} / \mathrm{m}^{2}$. The quadrupole moment of an excited iron nucleus is 0.28 barn $\left(0.28 \cdot 10^{-28} \mathrm{~m}^{2}\right)$ and this field creates $\Delta Q$ of $12.6 \mathrm{~mm} / \mathrm{s}$. As can be seen in Fig. 4, the $\Delta Q$ values are significantly lower, thus only a portion of $3 d$ electron charge takes part in creating the EFG. Table 1 shows the portion of $3 d$ electron charge participating in creating the EFG corresponding to observed $\Delta Q$ values. Having assessed $\Delta n_{3 d}$, we can easily find $\Delta n_{4 s}$ as well. The data obtained suggest that thermal changes of hyperfine parameters require quite small changes in the electronic density.

Having reached the nitrogen ring, the charge fluctuations can also be transferred to iron ions. Thus, the 


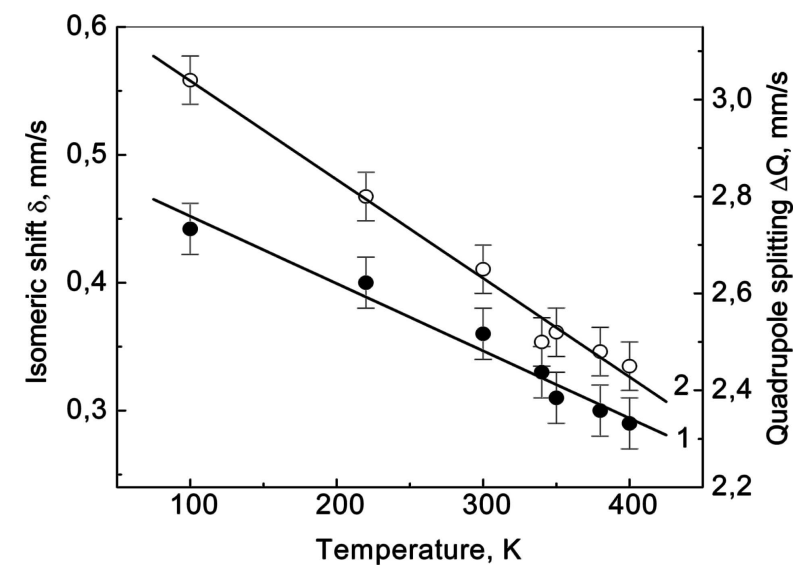

(a)

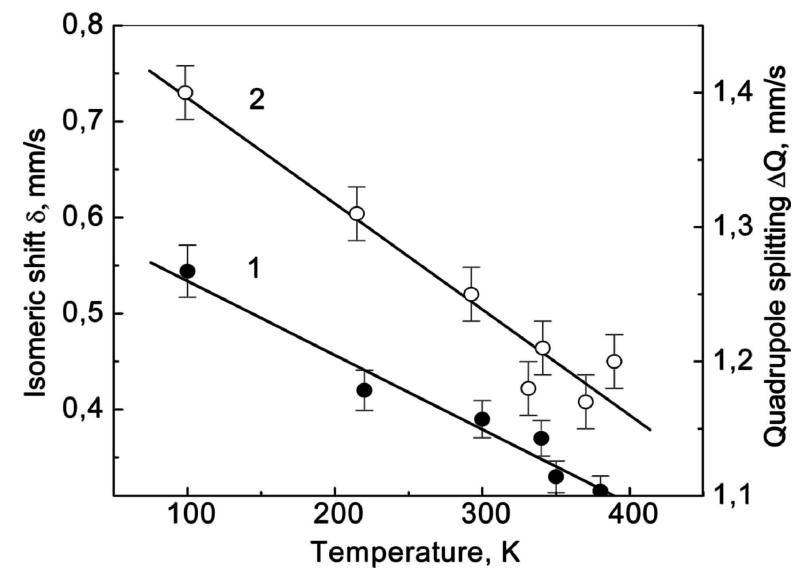

(b)

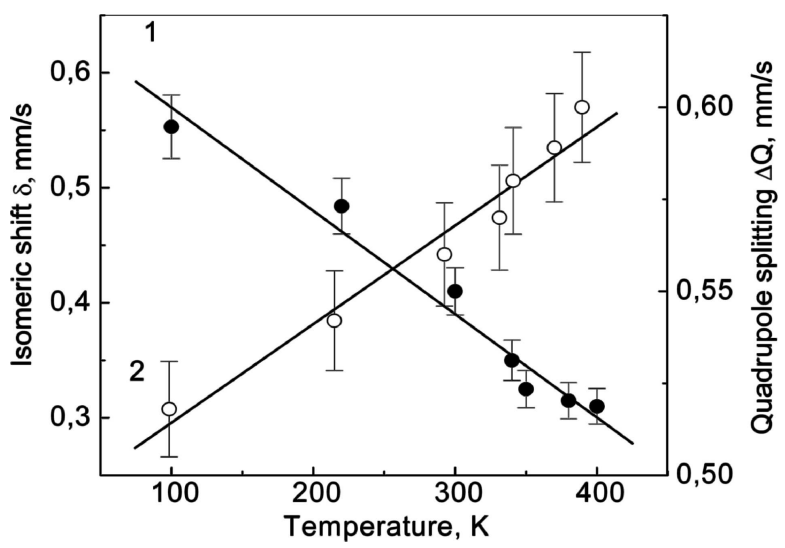

(c)

Fig. 4. Temperature dependence of the isomeric shift $\delta(1, \bullet)$ and quadrupole splitting $\Delta Q(2, \circ)$ : (a) $\mathrm{Fe}^{2+}$, (b) $\mathrm{Fe}^{2.5+}$, (c) $\mathrm{Fe}^{3+}$.

density alterations of $3 d$ or $4 s$ electrons in central $\mathrm{Fe}$ ions depend on the surrounding axial ligand dynamics as well as on the accepting and donating properties of atoms. The lifetime of various oxidation states is dependent on the height of separating energy barrier that can be overcome by the resonance tunnelling. The tunnelling process requires exact matching of electronic levels $\left(10^{-7} \mathrm{eV}\right)$, and as a result the process is
Table 2. Temperature dependence of lifetimes $\tau$ of Fe oxidation states in iron phthalocyanine.

\begin{tabular}{cccc}
\hline & \multicolumn{3}{c}{$\tau \cdot 10^{8}, \mathrm{~s}$} \\
\cline { 2 - 4 } Temperature & $\mathrm{Fe}^{2+}$ & $\mathrm{Fe}^{3+}$ & $\mathrm{Fe}^{2.5+}$ \\
\hline $100 \mathrm{~K}$ & 2.2 & 7.9 & 1.6 \\
$220 \mathrm{~K}$ & 1.9 & 9.0 & 2.2 \\
$300 \mathrm{~K}$ & 1.6 & 10.0 & 2.0 \\
\hline
\end{tabular}

Table 3. Energy barriers separating iron ions with different oxidation numbers in iron phthalocyanine and the temperature dependence of the barriers.

\begin{tabular}{cccc}
\hline & \multicolumn{3}{c}{$\Delta E, \mathrm{eV}$} \\
\cline { 2 - 4 } Temperature & $\mathrm{Fe}^{2+} \leftrightarrow \mathrm{Fe}^{3+}$ & $\mathrm{Fe}^{3+} \leftrightarrow \mathrm{Fe}^{2.5+}$ & $\mathrm{Fe}^{2+} \leftrightarrow \mathrm{Fe}^{2.5+}$ \\
\hline $100 \mathrm{~K}$ & 1.3 & 2.5 & 1.5 \\
$220 \mathrm{~K}$ & 4.8 & 4.8 & 1.3 \\
$300 \mathrm{~K}$ & 5.6 & 8.0 & 0.4 \\
\hline
\end{tabular}

very slow. The lattice vibrations broaden the electronic levels up to $0.05-0.1 \mathrm{eV}$ and the charge transfer proceeds quite quickly. The lifetimes of oxidation states were calculated making use of Eq. (5) and they are listed in Table 2, while Table 3 contains experimentally determined energy barriers separating the oxidation states. The peak with intermediate values of $\delta$ and $\Delta Q$ can be attributed to $\mathrm{Fe}^{2.5+}$ ions. This is not an intermediate $\mathrm{Fe}^{2.5+}$ oxidation state but the state reflecting the electronic charge redistribution between $\mathrm{Fe}^{2+}$ and $\mathrm{Fe}^{3+}$ ions that occurs faster than in $10^{-9} \mathrm{~s}$. In the region of low temperatures, this intermediate state is mainly formed in the chain $\mathrm{Fe}^{2+} \rightarrow \mathrm{Fe}^{3+}$ rather than $\mathrm{Fe}^{3+} \rightarrow \mathrm{Fe}^{2+}$. Quasiintermediate state peaks do not disappear when there are no $\mathrm{Fe}^{2+}$ ion peaks, and their area makes up $10-15 \%$ of the total spectrum. This demonstrates that at higher temperatures the chain $\mathrm{Fe}^{3+} \rightarrow \mathrm{Fe}^{2+}$ is active as well. The interaction of $\mathrm{Fe}^{3+}$ ions with phonons is markedly weaker as compared to $\mathrm{Fe}^{2+}$ ions. The iron ions are widely separated (about $0.5 \mathrm{~nm}$ ) and the direct electron exchange is very slow, if any [9]. Two chains are involved in the charge redistribution mechanism: "axial ligands - nitrogen ring" and "nitrogen ring - iron ion".

Pure states of $\mathrm{Fe}^{2+}$ and $\mathrm{Fe}^{3+}$ are observed when $\tau>\tau_{N}$, where $\tau_{N}$ is the time resolution of ${ }^{57} \mathrm{Fe}$ Mössbauer effect $\left(10^{-7} \mathrm{~s}\right)$. Since the principal redistribution phenomena occur in the chain "nitrogen ring iron ion", the amount of $\mathrm{Fe}^{2+}$ drops with increasing the frequency of the electronic charge transfer, and that of the intermediate $\mathrm{Fe}^{2.5+}$ state increases. In the exchange process, more $\mathrm{Fe}^{2+}$ ions will release an electron to molecular orbitals with temperature, thus increasing 
the amount of quasistable $\mathrm{Fe}^{3+}$ states. The number of $\mathrm{Fe}^{3+}$ ions increases with temperature, and having reached the $310 \mathrm{~K}$ temperature it abruptly jumps up and makes up $80-90 \%$. The population of the intermediate valence state reaches the maximal value at $220 \mathrm{~K}$. Only $12 \%$ of $\mathrm{Fe}^{2.5+}$ and $88 \%$ of $\mathrm{Fe}^{3+}$ ions are responsible for the spectrum recorded at $340 \mathrm{~K}$, and all this demonstrates a dynamic character of the phenomenon. After cooling down the same sample and recording the spectrum at room temperature, the percentage of ions is $26 \%$ of $\mathrm{Fe}^{2+}, 20 \%$ of $\mathrm{Fe}^{2.5+}$, and $54 \%$ of $\mathrm{Fe}^{3+}$. The temperature dependence of the quadrupole splitting and isomeric shift is presented in Fig. 4. It is known that the weakening of donating properties of $\sigma$-and $\pi$-bonds of axial ligands leads to the increased isomeric shift [16]. The quadrupole splitting increases by weakening the donating properties of $\sigma$-bonds of axial ligands or when the donor character of $\pi$-bonds increases. The linear relationship between $\delta$ and $\Delta Q$ for $\mathrm{Fe}^{2+}$ has a negative slope and it shows the acceptor-like process between axial ligands and the central iron ions. The coupling constant in iron between the amount of $s$ electrons and $\delta$ is negative, therefore, the $\delta$ value increases when the $s$ electron density at the nucleus decreases. The charge density depends on the number of $s$ electrons or on changes in screening by $3 d$ electrons. The character of population of electronic orbitals affects not only $\delta$ values but $\Delta Q$ values as well.

\section{Conclusions}

In summary, ${ }^{57} \mathrm{Fe}$ isotope-enriched $\beta$-iron phthalocyanine has been synthesized and studied using the Mössbauer spectroscopic method. It has been found that there is no single stable oxidation number in iron. Iron oxidation numbers observed in Mössbauer spectra are instantaneous. The thermodynamic equilibrium in the charge distribution is attained by virtue of continuous charge redistribution in the $\mathrm{Fe}-\mathrm{N}$ chain and within the macromolecule. The rate of charge redistribution is temperature-dependent. The correlation between the temperature behaviour of the isomeric shift and quadrupole splitting has been observed. At higher temperatures $(T>300 \mathrm{~K})$, the quasistable $\mathrm{Fe}^{3+}$ oxidation number is observed.

\section{References}

[1] G. de la Torre, P. Vazquez, F. Agullo-Lopez, and T. Torres, Phthalocyanines and related compounds:
Organic targets for nonlinear optical applications, J. Mater. Chem. 8, 1671-1683 (1998).

[2] Y. Shirota, Organic materials for electronic and optoelectronic devices, J. Mater. Chem. 10, 1-25 (2000).

[3] H. Wachtel, J.J. Andre, W. Bietsch, and J.U. von Schütz, Spin dynamics in oriented lithium phthalocyanine thin films investigated by pulsed electron spin resonance, J. Chem. Phys. 102, 5088-5093 (1995).

[4] M. Tian, T. Wada, H. Kimura-Suda, and H. Sasabe, Novel non-aggregated unsymmetrical metallphthalocyanines for second-order nonlinear optics, J. Mater. Chem. 7, 861-863 (1997).

[5] R. Göbl, A. Zentko, J. Kovac̀ et al., Magnetic properties of uranium ferrocyanides and ferricyanides, Czech. J. Phys. 50, 671-676 (2000).

[6] M. Evangelisti, J. Bartolome, L.J. de Jongh, and G. Filoti, Magnetic properties of $\alpha$-iron (II) phthalocyanine, Phys. Rev. B 60, 144410-1-11 (2002).

[7] V. Gulbinas, Transient absorption of photoexcited titanylphthalocyanine in various molecular arrangements, Chem. Phys. 261, 469-479 (2000).

[8] E. Kuzmann, A. Nath, V. Chechersky et al., Mössbauer study of oxygenated iron-phthalocyanines, a precursor of magnetic storage material, Hyp. Interact. 139/140, 631-639 (2002).

[9] K. Gonzalez, R. Iraldi, and F. Gonzalez-Jimenez, Mössbauer study of factors in iron carbonitrides. Hyp. Interact. 28, 619-622 (1986).

[10] Mössbauer Spectroscopy, eds. P.E. Dickson and F.J. Berry (Cambridge University Press, Cambridge, 1986).

[11] I.P. Suzdalev, Gamma-Resonance Spectroscopy of Proteins and Model Compounds (Moscow, Nauka, 1988) [in Russian].

[12] V.M. Derkatcheva, N.I. Budina, N.G. Meshriakova et al., New method of preparing iron phthalocyanine, Zh. Neorg. Khim. [J. Inorg. Chem. (USSR)] 26, 16871690 (1981).

[13] F. van der Woude and K.W. Maring, in: The Electronic and Magnetic Properties of Iron sp Element Alloys, Proceedings of International Conference on Mössbauer Spectroscopy (Bucharest, 1977) pp. 11321161.

[14] A.R. Miedema and P.T. de Chatel, Theory of Alloy Phase Formation, ed. L.H. Bennet (Met. soc. AIME, Ohio, 1979).

[15] Ch.P. Slichter, Principles of Magnetic Resonance (Mir, Moscow, 1967) [in Russian].

[16] H. Inoue, Y. Matsubayashi, T. Shirai, and E. Fluck, Mössbauer spectroscopic characterization of iron chlorophyllins, Hyp. Interact. 29, 1403-1406 (1986). 


\title{
METALO BŪSENOS KAITA Fe FTALOCIANINE
}

\author{
A. Amulevičius, V. Remeikis, A. Undzėnas
}

Fizikos institutas, Vilnius, Lietuva

\section{Santrauka}

Susintetintas ${ }^{57} \mathrm{Fe}$ izotopu praturtintas geležies ftalocianinas ir tirtas Mesbauerio spektroskopijos metodu 100-350 K temperatūros intervale. Buvo stebimos tarpinès Fe oksidacijos būsenos ir nustatyta, kad krūvio persiskirstymo sparta priklauso nuo temperatūros.
Parodytas sąryšis tarp izomerinio poslinkio temperatūrinès elgsenos ir kvadrupolinio suskilimo. Fe oksidacijos laipsnis siejamas su elektrono krūvio fliuktuacijomis bei ligandu gebèjimu priimti ir atiduoti elektronus. Ivertinti $\mathrm{Fe}$ oksidacijos būsenas skiriantys energijos barjerai. 